\title{
Representações do agir professoral de estagiários em relatórios de estágio supervisionado: o que dizem os professores em formação sobre seu trabalho planificado?
}

\author{
Rosivaldo Gomes \\ Universidade Federal do Amapá \\ rosivaldounifap12@gmail.com
}

\section{Resumo}

Este artigo apresenta uma análise a respeito do agir docente de professores de Língua Portuguesa em formação inicial em contexto de estágio supervisionado a respeito de representações discursivas do trabalho planificado (MACHADO, 2005) realizado por esses sujeitos. O estudo sustenta-se em discussões sobre estágio supervisionado como objeto de estudo (SILVA, 2014; GURGEL; LEURQUIN, 2016; BORELLI; PESSOA, 2019) e no quadro epistemológico do Interacionismo Sociodiscursivo a partir dos conceitos de agir e trabalho docente (BRONCKART, 2006, 2008; ABREU-TARDELLI, 2006; BRONCKART, MACHADO, 2004; MACHADO 2008; MACHADO; BRONCKART 2005, 2009). A pesquisa configura-se como qualitativo-interpretativista (DENZIN; LINCOLN, 2006), do tipo documental e situa-se no campo da Linguística Aplicada. O corpus analisado é constituído por segmentos temáticos (BULEA, 2010) de três relatórios produzidos por acadêmicos, referentes à disciplina de Estágio Supervisionado em Língua Materna/Portuguesa I, ministrada no Curso de Letras Português/Francês na Universidade Federal do Amapá, no ano de 2019. Os resultados demonstram que as/os professoras/es em formação, a partir de seu agir professoral, planificam e ressignificam seu trabalho não só com base no que está prescrito nos documentos oficiais, mas também em função das suas necessidades de ensino e das necessidades e possibilidades de aprendizagem dos alunos.

Palavras-chave: Agir professoral. Estágio. Relatórios. Formação inicial de professores.

\section{Abstract}

This paper presents an analysis about the teaching action of Portuguese language teachers in initial training in the context of supervised internship regarding discursive representations of the planned work (MACHADO, 2005) performed by 
these subjects. The study is based on discussions about supervised internship as an object of study (SILVA, 2013; GURGEL; LEURQUIN, 2016; BORELLI; PESSOA, 2019) and in the epistemological framework of Sociodiscursive Interactionism from the concepts of acting and teaching work (BRONCKART, 2006, 2008; ABREUTARDELLI, 2006; BRONCKART, MACHADO, 2004; MACHADO 2008; MACHADO; BRONCKART 2005, 2009). The research is configured as qualitativeinterpretive (DENZIN; LINCOLN, 2006, MOITA LOPES, 1994; BORTONIRICARDO, 2018), of the documentary type and is located in the field of Applied Linguistics. The analyzed corpus consists of thematic segments (BULEA, 2010) of three reports produced by academics, referring to the discipline of Supervised Internship in Mother/Portuguese Language I, taught in the Portuguese/French Courses at the Federal University of Amapa, in 2019. The results show that the teachers/es in formation, based on their teaching action, plan and resignify their work not only based on what is prescribed in the official documents, but also on the basis of their teaching needs and the learning needs and possibilities of the students.

Keywords: Teacher actions. Internship. Reports. Initial teacher education.

\section{Introdução}

Situado no campo da Linguística Aplicada e tendo como foco o agir professoral/docente representado/reconfigurado na e pela linguagem (BRONCKART, 2008), este artigo, que conta com algumas discussões de uma pesquisa maior ${ }^{1}$ apresenta uma análise de representações/reconfigurações do agir de professoras/es em formação inicial, acadêmicas/os de um curso de Letras, a respeito do trabalho por elas/es desenvolvido durante a realização da disciplina de Estágio Supervisionado I em Língua Materna/Portuguesa.

O estudo sustenta-se teórica e metodologicamente em discussões sobre estágio supervisionado como objeto de pesquisa no campo da Linguística Aplicada (SILVA, 2014; GURGEL; LEURQUIN, 2016; BORELLI; PESSOA, 2019), no Interacionismo Sociodiscursivo a partir dos conceitos de agir e trabalho docente (BRONCKART, 2006, 2008; AMIGUES; 2004;

${ }^{1}$ A pesquisa está sendo desenvolvida no Programa de Pós-graduação em Linguística da Universidade Federal do Ceará e no grupo de Pesquisa Gepla/UFC, sob a supervisão da profa. Dra. Eulália Leurquin. O estudo é financiado pelo Programa Nacional de Pós-Doutorado/Capes (PNPD/CAPES) e tem como foco a formação inicial de professores e o agir professoral de estudantes de Letras. 
ABREU-TARDELLI, 2006; BRONCKART, MACHADO, 2004; BUENO, 2007, BRONCKART, 2004, 2006, 2008; MACHADO 2008; MACHADO; BRONCKART 2005, 2009) e configura-se como um estudo qualitativointerpretativista.

Para direcionar a análise proposta neste artigo, o seguinte questionamento guia as reflexões que são apresentadas: i) como os professores em formação representam, em seus relatórios de regência, o agir professoral relativo ao trabalho planificado desenvolvido por eles durante o contexto de realização de Estágio Supervisionado em Língua Portuguesa?

Para responder a esse questionamento, a análise centra-se em alguns Segmentos de Tratamento Temático (STT), conforme propõe Bulea (2010), de três relatórios que apresentam, de forma discursiva, representações referentes desse agir. Nesses segmentos, consideraremos as dimensões do agir professoral das/os estagiárias/os em relação ao que selecionaram para ser ensinado a partir do trabalho planificado. Para isso, partiremos de uma releitura das categorias da Semântica do Agir (BRONCKART, 2006, 2008).

Para atender ao objetivo proposto, o artigo foi organizado da seguinte forma: i) apresentamos uma rápida discussão sobre estágio supervisionado; ii) tratamos da definição e configurações do agir nos e pelos textos; iii) apresentamos as dimensões que constituem o trabalho docente; iv) trazemos a metodologia de geração dos dados e v) tratamos da análise dos dados obtidos por meio dos relatórios de estágio e, por fim, apresentamos nossas considerações finais.

\section{A configuração do estágio curricular: integração de saberes para ensinar e para o ensino}

No contexto da LA contemporânea, com inclinação para questões educacionais, tem-se desenvolvido modos outros de se fazer pesquisa que buscam (re)construir sócio-histórias de ensino, de aprendizagem e de formação de professores, entre outros temas e objetos de pesquisa a partir de diferentes abordagens teóricas e de complexas redes de (re)significações, mobilizadas por pesquisadores para darem conta desses temas e objetos. Nesse sentido, um desses temas que tem despertado o interesse de muitos linguistas aplicados é o estágio supervisionado no ensino de línguas 
(MILLER, 2013; KLEIMAN, 2013; SILVA, 2014; CAVALCANTI, 2013; MOITA LOPES, 2013).

Em uma perspectiva decolonial (BORELLI; PESSOA, 2019) consideramos que o estágio supervisionado curricular obrigatório, nas licenciaturas, deve ser visto/compreendido não somente como um momento oportuno para que a/o acadêmica/o possa pôr em práticas um conjunto de saberes para o ensino, apreendidos durante sua formação inicial, mas também como um momento em que essas/es professoras/es, em formação, podem experienciar a cultura escolar e vivenciar as potencialidades, os desafios e as dificuldades que são colocadas para aqueles que estão em suas práticas diárias em sala de aula.

Nesse sentido, assim como Borelli e Pessoa (2019, p. 76), consideramos o estágio como um momento de saída da/o acadêmica/o da universidade para buscar os saberes construídos e mobilizados no ambiente escolar, mas também como um momento de se pôr em diálogo, com esses saberes, aqueles apreendidos na universidade pois "é nesse encontro com professores/as e estudantes da escola que nós, professores/as da universidade, e nossos/as professores/as licenciandos/as construímos o conhecimento que embasa as nossas reflexões" para uma formação crítica e reflexiva.

Com base em Silva (2012), consideramos que as disciplinas de estágio não podem se configurarem como os únicos momentos responsáveis pelo trabalho com os saberes docentes orientadores da prática profissional do professor em formação, já que a relação entre o saber-fazer e o contexto de sala de aula da educação básica requer outros momentos que possam possibilitar as/aos professoras/os, em formação, compreender a dinâmica pedagógica/didática, política, social e cultural que engendram a organização do espaço da escola e as práticas de ensino do letramento escolar.

No que diz respeito à escrita do relatório de estágio supervisionado, Silva (2012, p. 31) também propõe que devamos entender esse gênero discursivo para além do sentido que comumente lhe é atribuído, o de "instrumento para justificar atribuição de notas ou conceitos por docentes responsáveis pelas disciplinas de estágio supervisionado", pois trata-se, na verdade, de um instrumento que pode funcionar como "mediador da construção de uma prática de reflexão crítica sobre a ação profissional, no cotidiano do trabalho do professor". 
Assim, compreendemos que os relatórios de estágio podem revelar indícios/representações do agir professoral das/os professoras/es em formação sobre o trabalho desenvolvido no contexto de sala aula, mas também podem evidenciar, conforme propõe Leurquin (2013), que em sala de aula não está em jogo apenas o saber-fazer, constitutivo do trabalho do professor, mas também objetivos, intenções, limitações, que levam o professor em formação a um a um poder-fazer, querer-fazer e dever-fazer em relação ao seu trabalho.

O conjunto de informações, que são semotizadas na e pela linguagem nos relatórios de estágio, permitem reconhecer e entender, portanto, representações e reconfigurações do agir professoral das/estagiárias/os e o repertório didático por elas/es mobilizado nesse agir quanto ao trabalho que efetivamente realizam em sala de aula, pois nesse gênero, próprio das práticas de escrita acadêmica, são materializadas, conforme pontua Gurgel (2020) muitas das representações sociodiscursivas que os professores em formação inicial (com)partilham sobre o seu agir e sobre o seu desenvolvimento profissional.

\section{Configurações do agir nos e pelos textos}

Baseando-nos em Lousada, Abreu-Tardelli e Mazzillo (2007) consideramos que o agir configura-se como uma unidade analítica que pode auxiliar na compreensão das atividades do trabalhado educacional/do professor, representado nos e pelos textos, em nosso caso, nos relatórios de estágio supervisionado.

Nesse sentido, o agir ou agir-referente é um termo mais geral e neutro e configura-se como qualquer forma de intervenção orientada de um ou vários seres humanos no mundo e a partir de representações sociais e individuais que mobilizamos (BRONCKART, 2009 [1999], 2006, 2008).

Bronckart (2008) baseando-se também em pressupostos da Psicologia da Linguagem faz a distinção entre um agir geral/praxiológico relacionado, nesse caso, com atividades gerais/coletivas (sociais) como, por exemplo, "nós planejamos os materiais didáticos" e em um agir verbal/linguageiro ligado, neste caso, com ações de linguagem/linguageiras individuais, como, por exemplo, "eu trabalhei com o gênero charge em sala de aula com os alunos". 
Representações do agir professoral de estagiários...

Já o termo ação configura-se como uma sequência ordenada de intervenções realizadas por um actante e que são marcadas por uma dimensão motivacional e intencional (individual) e atividade também é desencadeada por uma dimensão motivacional e intencional, mas a nível coletivo (BRONCKART, 2006, 2008).

Outros termos também importante no campo do ISD são actante, que configura-se como qualquer ser humano que se encontra implicado no agir; ator que faz remissão à configuração de um ser/indivíduo como responsável pelo agir (podendo ser o actante) e que, portanto, apresenta capacidades, motivos e intenções (quase sempre pessoais) e, por fim, agente que não apresenta as características do ator, ou seja, não apresenta capacidades, motivos e intenções para agir e é condicionado a razões e propósitos de um coletivo (BRONCKART, 2008b).

A partir dessas definições, Bronckart (2009[1999]) propõe a análise do agir humano a partir de produções verbais (agir verbal/linguageiro), as quais são realizadas pelo próprio ser humano durante o curso do agir, isto é, durante a realização de ações. Porém, esse agir não pode ser "capturado" como de fato foi realizado e, por isso, Bronckart $(2006,2008)$ propõe que possam ser analisadas as representações do agir nos e pelos textos e, nesse sentido, qualquer texto pode ser objeto de interpretação do agir.

Assim, o agir linguageiro torna-se importante no quadro do ISD na relação com a ideia de texto, pois conforme pontuam Bronckart (2006, 2008, 2010), Bronckart e Bulea (2008), o texto configura-se como uma unidade comunicativa interativa englobante e manifestação linguística/empírica das ações de linguagem e, portanto, veículo de uma mensagem organizada que tende a produzir um efeito de coerência sobre o destinatário, em um determinado espaço e em um determinado tempo (BRONCKART, 2006). Nessa perspectiva, o agir linguageiro materializa-se/traduz-se em textos (BRONCKART, 2008, p. 87).

Devido a essa caracterização, o texto deve ser estudado/analisado a partir de uma perspectiva "descendente" (BRONCKART, 2008, 2006), ou seja, indo de propriedades que envolvem o contexto de produção até unidades linguístico-enunciativas que traduzem o agir realizado pelo produtor/actante (BRONCKART, 2009[1999]) e materializado na textualidade.

A ideia de contexto torna-se fundamental para a análise do agir professoral, pois conforme salientam Leurquin e Mendes (2017), em seu agir 
o professor mobiliza representações tanto do mundo físico (de sala de aula, do momento em que as ações ou atividades estão ocorrendo) quanto do mundo social e subjetivo), sendo que a realização desse agir e, portanto, do trabalho do professor, é marcada por modalizadores que moldam esses agir em sala de aula (LEURQUIN, 2013), isto é, além do saber-fazer, característico da profissão do professor, entram em jogo também o deversaber, o querer-fazer e o poder-fazer.

\section{As dimensões do trabalho docente}

As noções de trabalho e dimensões do trabalho do professor são discutidas, neste artigo, a partir de questões oriundas do campo da Ergonomia da Atividade (AMIGUES, 2004), da Clínica da Atividade (CLOT, 1999; FAITA, 2004) e de alguns construtos teóricos do ISD (BRONCKART, 2006, 2008; MACHADO, 2007; BRONCKART, MACHADO, 2004; MACHADO, BRONCKART, 2009; MACHADO, 2009).

Para Bronckart $(2006,2008)$ apesar das inúmeras acepções que podem ser designadas ao termo trabalho, este pode ser compreendido, em sentido mais restrito, como um tipo de atividade ou prática humana configurado como formas de organização coletiva, cujo destino volta-se para a assegurar a sobrevivência econômica dos membros de um grupo.

Ainda nesse sentido, conforme pontuam Amigues (2004) e Bronckart (2006) na perspectiva ergonômica houve a preocupação em se estabelecer a diferença entre o trabalho prescritivo e o trabalho realizado, sendo o primeiro relativo ao trabalho tal como ele é predefinido/instituído em diversos manuais ou documentos que apresentam instruções, modelos, modos de emprego; já o segundo termo - trabalho realizado - designa as características efetivas, isto é, que materializam as 'diversas tarefas que são realizadas pelos trabalhadores em situação concreta' (BRONCKART, 2006, p. 2008).

Na perspectiva da Clínica da Atividade (CLOT, 2007) o trabalho real de um ser humano seria seu trabalho pensado, projetado, possível de ser realizado, mas também impedido por forças externas à própria realização em algumas circunstâncias. 
Um ganho apontado na perspectiva da Clínica da Atividade, conforme pontua Bronckart (2006), é o fato de ser considerado, na vertente do trabalho teórico elou prescritivo, a transposição das noções bakhtinianas de gênero e estilo para a definição de gêneros profissionais, os quais configuram as ações realizadas pelo trabalhador, no caso do trabalho do professor esses gêneros dizem respeito aos materiais, planos de ensino, de aula, apostilados que ele elabora para planificar suas ações didáticas.

No contexto do ISD e tomando por bases essas abordagens teóricas, Machado (2007) e Machado e Bronckart (2009) partem da hipótese de que o trabalho do professor, especificamente o seu trabalho em sala de aula, mobiliza seu ser integral, isto é, em suas diferentes dimensões (físicas, cognitivas, linguageiras, afetivas, práticas, emocionais, etc.).

Assim, o trabalho do professor, conforme os autores, caracteriza-se de forma pessoal, interacional, já que, ao agir sobre o meio, o trabalhador o transforma e é por ele transformado. Além disso, é mediado por instrumentos materiais e simbólicos; é interpessoal, posto que envolve sempre uma interação com outrem, colegas professores, gestores; impessoal, já que as tarefas são prescritas ou prefiguradas por instâncias externas e é transpessoal, uma vez que é guiado por "modelos do agir" de cada 'métier' (MACHADO; BRONCKART, 2009, p. 36-37).

Tratando do trabalho do professor como uma atividade discursiva, Machado (2009) propõe também, com base nas discussões apresentadas anteriormente, que esse deva ser analisado a partir de três níveis: a partir do trabalho prescritivo, do trabalho planificado ou planejado e do trabalho efetivamente realizado. A esses níveis elencados pela autora acrescentamos também o trabalho real, tal como definido por Clot (2007).

Assim, o trabalho prescritivo diz respeito a todas as prescrições que direcionam e regularizaram o agir do trabalhador, neste caso, o professor (MACHADO, 2009). Essas prescrições são instituídas por órgãos governamentais e estabelecem as tarefas a serem realizadas pelo professor e, nesse sentido, para Machado e Lousada (2010), as prescrições não podem se descartas, uma vez que são configuradas como artefatos que auxiliam o trabalho docente e, portanto, não podem ser vista de forma negativa.

Desse modo, o trabalho prescrito configura-se como "um conjunto de normas e regras, textos, programas e procedimentos que regulam as ações do trabalhador" (MACHADO, 2009, p. 80), sendo que essas prescrições se originam de instâncias que são tanto externas quanto internas ao trabalho 
docente. Em nosso caso, com relação ao trabalho das/os estagiárias/os do Curso de Letras, podemos dizer que estão em jogo prescrições de instâncias:

1) de nível acadêmico a partir de prescrições, tanto externas (nacionais) quanto internas (locais, de cada IES), que regularizam e normatizam o estágio curricular a partir de Diretrizes, Pareceres, Instruções Normativas, Resoluções, etc. e de prescrições de disciplinas ${ }^{2}$ que apresentam teorizações sobre o como ensinar e que devem ser considerado pelos acadêmicos no momento da didatização e da modalização de conteúdos para o ensino;

2) de nível da educação básica com prescrições instituídas pelos textos de documentos oficiais nacionais/federais, como os PCN, 1998, a BNCC, 2018, que prescrevem quais conteúdos, objetos e objetivos de ensino que devem ser considerados para o ensino;

3) de nível local com prescrições de documentos elaborados pelas Secretarias de Educação a partir de Diretrizes Curriculares Estaduais e Municipais e pelas prescrições estabelecidas pelos Projetos Político-Pedagógicos escolares) e;

4) da (re)apropriações ou reconcepções ${ }^{3}$ prescritivas realizadas pelo próprio professor como, por exemplo, os conteúdos que ele selecionou para serem ministrados em sala de aula e que devem ser considerados e incorporados no planejamento da ação de intervenção dos/as estagiários/as.

Já o trabalho planificado configura-se como um desdobramento do trabalho prescrito, ou seja, é a planificação realizada pelo professor daquilo que é proposto, por exemplo, pelos documentos oficiais para ser ensinado. Nesse sentido, é o trabalho planificado que comporta um conjunto de textos pré-figurados das ações do trabalhador (MACHADO, 2004, p. 41), os quais explicitam "o conjunto de tarefas, seus objetivos, suas condições materiais e a forma de desenvolvimento das ações projetadas pelo próprio trabalhador

${ }^{2}$ Em nosso caso, Disciplinas como Didática Geral, Didática da Língua Materna I e II e a própria Disciplina de Estágio Supervisionado I.

${ }^{3}$ Conforme Machado e Lousada (2010) e Lousada (2006) o professor, frente as prescrições externas que também envolvem o seu trabalho, realiza sempre um recorte pessoal a ser por ele seguido em seu contexto de ensino. A isso as autoras denominam de reconcepção que gera, pelo professor, uma autoprescrição, ou seja, ele redefine e traça novas concepções para essas prescrições. 
para atingir seus objetivos". Trata-se, portanto, de textos que constituem o "planejamento do agir docente, elaborados pelo próprio professor. Seria o trabalho prescrito, mas de ordem interna - uma autoprescrição" (BARROS, 2013, p. 13).

Com relação ao trabalho planificado/planejado pelas/os estagiárias/os, professoras/trabalhadoras/es em formação, esse configura-se a partir da elaboração, primeiramente, de um projeto de intervenção a ser desenvolvido na escola-campo durante momento da regência. Além desse projeto, compõem o trabalho planejado um ou vários planos de aula e um conjunto de atividades de práticas de leitura, de produção textual, de análise linguística e oralidade, que podem ser organizadas em uma Sequência didática.

A terceira dimensão diz respeito ao trabalho de fato realizado pelo trabalhador, pois na constituição das atividades de trabalho institucional, seja público ou privado, o trabalhador depara-se com restrições, normas e com aquilo que é planejado para ser executado. Nesse sentido, o trabalhador apoia-se nessas normas que são estabelecidas a partir de prescrições e/ou orientações para efetivar o chamado trabalho realizado, isto é, para realizar um "conjunto de condutas (verbais ou não verbais) efetivamente observáveis na situação [de trabalho], que sempre vai apresentar algum distanciamento em relação ao que lhe foi prescrito" (MACHADO, 2004, p. 41).

No caso dos/as estagiários/as, o trabalho realizado diz respeito às ações e atividades efetivamente realizadas por esses actantes no contexto de sala de aula com base nas prescrições que fundamentam a planificação das atividades por eles/elas elaboradas para serem desenvolvidas.

Por fim, a última dimensão, o trabalho real, apesar de incorporar o trabalho realizado diferencia-se deste, pois conforme pontua Clot (2007, p.93) “o real é a ação de realização - jamais totalmente previsível - que põe o sujeito em contato com as realidades objetivas do mundo das coisas e dos homens, ocasiões para e obstáculos ao [ ] seu desenvolvimento". Nesse sentido, o trabalho real configura-se como aquilo que é possível, impossível, que poderia ser feito pelo trabalhador e que foi planificou para ser realizado, mas por algum motivo não foi, mas que o trabalhador gostaria de ter sido feito (LOUSADA, 2006).

Considerando o foco de análise deste artigo, interessa-nos compreender as representações do agir professoral das/dos estagiários de Língua Portuguesa a partir das dimensões do trabalho docente, sendo 
focalizado apenas o trabalho planificado/planejado, devido as poucas discussões que há sobre essa dimensão.

\section{Metodologia e releitura das categorias da Semântica do Agir}

Tendo em vista que o objetivo deste artigo é analisar o agir professoral de professores em formação inicial quanto às representações do trabalho que realizam em contexto de estágio, especialmente no que diz respeito ao trabalho planificado, este estudo configura-se como qualitativointerpretativista (DENZIN; LINCOLN, 2006; BORTONI-RICARDO, 2018), de caráter documental, por realizar uma análise a partir de documentos como os relatórios de estágio supervisionado e situa-se no campo da Linguística Aplicada.

O corpus analisado é constituído por três relatórios, aqui denominados de RL1 (relatório 1), RL2 (relatório 2) e RL3 (relatório 3), referentes à disciplina de Estágio Supervisionado em Língua Materna/Portuguesa I, ministrada em um curso de Letras Português/Francês em uma universidade publicada federal no ano de 2019. Nessa ocasião, atuávamos como supervisor da referida disciplina e acompanhávamos as/os acadêmicas/os junto às escolas-campo de realização do estágio.

Para a organização da análise dos dados referentes aos relatórios, considerados por nós como textos-fonte que revelam o agir-referente das/dos estagiárias/os, analisaremos apenas alguns Segmentos de Tratamento Temático (STT), conforme propõe Bulea (2010), os quais evidenciam representações/reconfigurações do agir professoral das/os estagiárias/os no que diz respeito ao trabalho planificado/de planejamento das ações a serem desenvolvidas durante o curso do agir referente ao trabalho realizado em sala de aula da educação básica durante o estágio.

Assim, acerca do agir em situação de trabalho e sua interpretação, compreendemos, tal como proposto por Bulea (2010), que os STT configuram-se como segmentos em que a/o estagiária/o tematiza seu agir desenvolvido em relação ao trabalho planificado, isto é, sobre o que foi por ela/ele planejado a partir tanto do projeto de intervenção quanto do conjunto de atividades de práticas de leitura, produção textual, análise linguística para ser executado durante o trabalho realizado em sala de aula. 
Representações do agir professoral de estagiários...

Esses segmentos são identificados como: a) Caracterização do agir e Preparação, desenvolvimento e realização do agir. Para a análise desses segmentos assumimos, assim como Bronckart e Machado (2004), Machado e Bronckart (2009) e Bronckart (2006, 2008), as categorias da Semântica do agir, uma vez que para a concretização desse trabalho estão em jogo pelo menos três dimensões do agir docente: motivacional, intencional e recursos do agir.

Assim, no contexto do ISD a Semântica do agir apresenta como conceitos centrais as noções de: agir-referente, atividade, ação, dimensões/planos: motivacional (determinantes externos e motivos), intencional (finalidade e intenções), recursos do/para o agir (instrumentos e capacidades) e os seres humanos que intervêm no agir: actante, ator e agente. Alguns desses conceitos já foram apresentados em outros momentos neste texto e, dessa maneira, apresentaremos apenas as dimensões/planos envolvidos no agir docente, os quais consideraremos para a análise dos dados.

Para Bronckart (2006, 2008), Bronckart e Machado (2004), em se tratando do agir, isto é, qualquer forma de intervenção humana no mundo, que pode ser de diferentes ordens e que, em contextos econômico-sociais específicos, podem se constituir num trabalho como é o caso do trabalho docente, autores destacam que o plano motivacional constitui-se por determinantes externos, de origem coletiva, de natureza material ou da constituição das representações sociais; e os motivos, que se configuram como as razões do agir interiorizadas por uma pessoa particular.

Já no plano da intencionalidade, os autores distinguem as finalidades, caracterizadas como a origem coletiva e socialmente validadas para o agir; e as intenções, que são os fins do agir, tais como são interiorizadas por uma pessoa em especial. Por fim, no plano dos recursos para o agir, Bronckart e Machado (2004, p. 155) distinguem os instrumentos, que podem ser ferramentas concretas ou modelos dos agir, disponíveis no meio social, das capacidades, que são os recursos mentais ou comportamentais que se atribuem a uma pessoa particular.

A partir de uma releitura dessas categorias propostas por Bronckart (2008) e Bronckart e Machado (2004), quanto à Semântica do agir, na análise dos dados focalizamos apenas: 
Quadro 1. Adaptação das categorias da Semântica do Agir

\begin{tabular}{|c|c|}
\hline $\begin{array}{l}\text { a) Caracterização, preparação e desenvolvimento do } \\
\text { agir/trabalho planificado. } \\
\text { Segmentos que tematizem o agir professoral a respeito do trabalho } \\
\text { planificado das/dos estagiários, representado nos relatórios: }\end{array}$ & $\begin{array}{c}\text { Representação } \\
\text { nos dados }\end{array}$ \\
\hline $\begin{array}{l}\text { 1. Segmentos que apresentem os determinantes que podem } \\
\text { influenciar o agir/trabalho de planificado } \\
1.1 \text { Determinantes externos - configurados de forma } \\
\text { coletiva, sendo de natureza material (parâmetros espaço- } \\
\text { temporais e materiais, representações sociais ou } \\
\text { prescrições, situações externas) }\end{array}$ & STT1.1.1 \\
\hline $\begin{array}{l}\text { 2. Segmentos que tematizam a intencionalidade do agir/trabalho } \\
\text { planificado } \\
2.1 \text { Intenções - diz respeito as escolhas (fins) particulares do } \\
\text { actante para o agir }\end{array}$ & STT2.2.1 \\
\hline $\begin{array}{l}\text { 3. Segmentos que tematizam os recursos para o agir/trabalho } \\
\text { planificado que servirá ou serviu ao trabalho realizado } \\
\text { 3.1 Instrumentos - ferramentas mobilizadas ou modelos do } \\
\text { agir disponíveis no ambiente social }\end{array}$ & STT3.3.1 \\
\hline
\end{tabular}

Fonte: Autoria própria.

A fim de compreendermos a configuração dessas dimensões no que diz respeito ao agir das/os estagiárias/os, passemos à próxima seção na qual apresentamos a análise dos dados.

\section{$6 \mathrm{O}$ agir professoral e o trabalho das/os professoras/es em formação no Estágio Supervisionado em Língua Portuguesa}

Iniciamos a análise dos dados a partir das representações presentes nos relatórios de estágio no que diz respeito ao agir professoral das/os professores estagiárias/os em relação ao trabalho planificado. Todavia, primeiramente apresentamos a configuração geral desse gênero.

No contexto do curso de Letras da Universidade Federal Amapá (Unifap) a produção do gênero relatório, enquanto escrita acadêmica, deve espelhar tanto o conjunto de ações observadas no contexto escolar, envolvendo desde aspectos físicos do espaço até os recursos materiais e humanos lá presentes, quanto aspectos didático-pedagógico, deve conter também uma descrição detalhada das aulas observadas, das práticas de 
ensino desenvolvidas pelas/os estagiárias/os durante a regência em sala de aula e um conjunto de informações adicionais, incluindo o projeto de intervenção que fora planejado e que serviu para a realização das atividades da regência.

Seguindo essa proposta de elaboração, os três relatórios analisados, que foram elaborados em duplas, trios ou individualmente, foram organizados, aqui, para efeitos de análise, da seguinte forma:

1) identificação do relatório a partir de siga (RL1, RL2, R3) e de seus produtores ${ }^{4}$;

2) elementos composicionais presentes nos relatórios;

3) ano da turma de atuação;

4) conteúdos trabalhados a partir dos eixos de ensino selecionados e

5) projeto de intervenção.

O conjunto das informações presentes no quadro 3, já de início, fornece algumas pistas a respeito do agir das/dos professoras/es estagiárias/os em relação ao trabalho planificado que realizaram antes da intervenção na escola. Assim, do ponto de vista da caracterização desse agir/trabalho, vemos que para a planificação das atividades foram selecionados pelas/os estagiárias/os três gêneros textuais que estão diretamente relacionados com algumas práticas de linguagem/eixos de ensino, conforme proposto por documentos oficiais que prescrevem o ensino de Língua Portuguesa.

Além disso, a escolha por esses gêneros e eixos não ocorre de maneira aleatória, pois nos relatórios encontramos segmentos que tematizam representações do agir das/os estagiárias/os em relação a essa escolha, conforme os segmentos a seguir que foram retirados das seções de desenvolvimento do relatório, mais especificamente da parte relativa à descrição das atividades desenvolvidas durante a regência.

${ }^{4}$ Por questões éticas da pesquisa, as/os professoras/es em formação estão sendo identificados com nomes fictícios. Além disso, todos participantes da pesquisa assinaram um Termo de Consentimento Livre e Esclarecido (TCLE), em conformidade com a resolução do CNS, $n^{\circ}$ 510, DE 07 DE ABRIL DE 2016 e com as normativas do Comitê de Ética da Unifap. 
Quadro 2. Sistemática de organização dos relatórios

\begin{tabular}{|c|c|c|c|c|}
\hline Identificação & Elementos & Ano & Conteúdos & Projeto de intervenção \\
\hline $\begin{array}{l}\text { RL1 } \\
\text { Brenda } \\
\text { Paula } \\
\text { Gustavo }\end{array}$ & \multirow{3}{*}{$\begin{array}{l}\text { Resumo } \\
\text { Introdução } \\
\text { Desenvolvimento com: } \\
\text { Projeto de intervenção com as } \\
\text { atividades de prática } \\
\text { Descrição da escola } \\
\text { Descrição da observação (espaço } \\
\text { físico) } \\
\text { Descrição da observação das aulas } \\
\text { Descrição da regência (Atividades } \\
\text { desenvolvidas) } \\
\text { Considerações finais e avaliação da } \\
\text { prática } \\
\text { Anexos e Apêndices }\end{array}$} & $\begin{array}{l}6^{\circ} \text { ano } \\
\text { E.F. II }\end{array}$ & $\begin{array}{l}\text { Gênero textual cartaz } \\
\text { Concordância nominal } \\
\text { Práticas de produção escrita e } \\
\text { leitura }\end{array}$ & $\begin{array}{l}\text { Produzindo o gênero cartaz } \\
\text { nas aulas de Língua } \\
\text { Portuguesa }\end{array}$ \\
\hline $\begin{array}{l}\text { RL } 2 \\
\text { Carla } \\
\text { Amanda }\end{array}$ & & $\begin{array}{l}1^{\circ} \text { ano } \\
\text { E. M. }\end{array}$ & $\begin{array}{l}\text { Carta do Leitor } \\
\text { Práticas de produção escrita e } \\
\text { leitura }\end{array}$ & $\begin{array}{l}\text { Trabalhando com gênero } \\
\text { Carta do Leitor }\end{array}$ \\
\hline $\begin{array}{l}\text { RL } 3 \\
\text { Carmem }\end{array}$ & & $\begin{array}{l}6^{\circ} \text { ano } \\
\text { E.F. II }\end{array}$ & $\begin{array}{l}\text { Gênero textual manifesto } \\
\text { Práticas de produção textual } \\
\text { Leitura e análise linguística }\end{array}$ & $\begin{array}{l}\text { Proposta Didática para se } \\
\text { trabalhar o gênero Manifesto }\end{array}$ \\
\hline
\end{tabular}

Fonte:Autoria própria

A escolha por esses gêneros e eixos não ocorre de maneira aleatória, pois nos relatórios encontramos segmentos que tematizam representações do agir das/os estagiárias/os em relação a essa escolha, conforme os segmentos a seguir que foram retirados das seções de desenvolvimento do relatório, mais especificamente da parte relativa à descrição das atividades desenvolvidas durante a regência. 
Nessa seção, enunciativamente, esses atores (estagiárias/estagiários) representam a caracterização do agir/trabalho planificado que realizaram, apresentando os saberes prescritivos que por eles foram mobilizados para a concretização do planejamento das ações didáticas para a intervenção que foi realizada em sala de aula, conforme os destaques em negrito:

\section{RL1}

STT1 - Caracterização do agir

STT1.1.1 (...) as atividades desenvolvidas no decorrer da regência contaram com a aplicação do tema referente ao gênero textual 'Cartaz' em conjunto com o conteúdo de concordância nominal. Optamos trabalhar com esses conteúdos pois ambos estão presentes na disciplina de Língua Portuguesa do $6^{\circ}$ ano do ensino fundamental - anos finais e $\underline{\underline{\mathrm{em}}}$ função do pouco tempo disponibilizado pelas professora (...) a escolha do gênero cartaz subsidiou-se também a partir da recomendação da Base Nacional Comum Curricular ${ }_{2}$ a qual orienta que é fundamental que o aluno do $6^{\circ}$ ao $9^{\circ}$ ano do ensino fundamental desenvolva a habilidade (...) $\underline{\mathrm{o}}$ planejamento das atividades foi elaborado também de acordo com o caderno de planejamento da professora regente da turma, para que, dessa maneira, pudéssemos dar continuidade aos conteúdos que ela já estava desenvolvendo.

\section{RL2}

STT1 - Caracterização do agir

STT1.1.1: O projeto desenvolvido fez parte das atividades propostas para a execução do estágio supervisionado em Língua Materna I, que foi aplicado em uma turma de $1^{\circ}$ ano do Ensino Médio da Escola Prof. Lucimar Amoras, no período de 07 (sete) de outubro de 2019 a 04 (quatro) de novembro do mesmo ano. Nesse sentido, o trabalho desenvolvido teve como objetivo contribuir para um aprofundamento de alguns gêneros textuais do campo de atuação jornalístico-midiático, especificamente a carta do leitor, seguindo o que está proposto na BNCC do Ensino Médio sobre o conhecimento dos gêneros que perpassam por esse campo de atuação, pois esse é o principal instrumento teórico utilizado para o ensino de língua portuguesa atualmente (...) apresentaremos as características do gênero e os elementos linguístico-gramaticais que podem ser identificados na carta do leitor. Trabalhamos mais esses conteúdos pois a 
professora precisaria também dar continuidade ao assunto que já havia iniciado com os alunos e aí incluímos questões de coesão textual também (...)

\section{RL3}

STT1 - Caracterização do agir

STT1.1.1: (...)fiz a observação junto a uma turma de $6^{\circ}$ ano do ensino fundamental (...) trabalhei o gênero "Manifesto", que além de promover a leitura de diversas temáticas, também é instigante para a prática da oralidade. Busquei fundamentar o projeto de intervenção na Base Nacional Comum Curricular de ensino fundamental (2018) que hoje é o principal documento que fundamenta a construção dos currículos da educação básica (....) a professora solicitou apenas que fosse possível a realização de um trabalho mais sistemático com as atividades de leitura igual como ela estava fazendo, pois muitos alunos ainda conseguiam desenvolver certas habilidades de leituras requeridas para alguns gêneros que elas estava trabalhando em sala (...)

Os segmentos acima mostram que o agir professoral das/os estagiários, quanto à caracterização do trabalho planificado que realizaram, é fortemente influenciado por determinantes externos (BRONCKART; MACHADO, 2004), neste caso, por prescrições que são estabelecidas por instâncias governamentais e documentos oficiais delas oriundos, como, por exemplo, a BNCC, conforme mostram os segmentos dos três relatórios (em negrito).

Contudo, de forma implícita, vemos também outros determinantes externos que estão implicados no agir dos atores, os quais partem do sistema de ensino local, neste caso, de instâncias como a escola e a Secretaria de Estado da Educação (SEED), como o fato dos conteúdos estarem presentes no quadro curricular do $6^{\circ}$ (RL1) e também “prescrições" propostas por outro agente, neste caso, pela professora, que sugere/propõe, direta ou indiretamente, alguns conteúdos que estava trabalhando e deseja que as/os estagiárias/os possam também contemplar em suas intervenções, como é evidenciado nos segmentos com sublinhado simples.

Além disso, ao recorrerem à $\mathrm{BNCC}$ e as demais prescrições, durantes o curso do agir (BRONCKART, 2008), consideramos que as/os professoras/es em formação reconhecem a importância desse documento e o que a escola propõe sobre quais objetos de ensino devem ser ensinados. 
Nesse sentido, as prescrições não são descartadas nem os saberes prescritivos oriundo desses documentos e instâncias, os quais fundamentam o ensino de língua materna/portuguesa no contexto em que esses actantes estão vivenciando práticas de desenvolvimento profissional.

Dessa maneira, conforme lembram Machado e Lousada (2010, p. 627) "essas prescrições, de modo teórico, não podem ser vistas como negativas, mas como artefatos disponibilizados para o professor e que podem facilitar o seu trabalho". Assim, as prescrições de documentos oficiais, como por exemplo, o usado pelas/os professoras/es estagiários, são fundamentais também para o desenvolvimento do trabalho de planificação que elas/eles realizaram, pois apresentam alguns direcionamentos sobre o saber-fazer (TARDIF, 2002; LEURQUIN, 2013).

Todavia, conforme nos faz lembrar Amigues (2004) algumas prescrições para o trabalho do professor são bastante vagas e imprecisas e, é nesse sentido, que o professor, para exercer seu trabalho, reconfigura tais prescrições em função das necessidades de aprendizagem das/os alunas/os, das condições de trabalho que lhe são oferecidas, das limitações de sua formação acadêmica, bem como de outros determinantes tanto externos quanto internos em relação ao seu agir para realização do trabalho docente.

Nos textos em análise, observamos que as/os estagiárias/os apesar de recorrem à $\mathrm{BNCC}$ e às demais prescrições, não se colocam com meros "tarefeiros" que consideram tais prescrições de forma ipsis litteris como estão postas nesse documento oficial, mas realizam adequações, recortes, reconfigurações, prescrevem tarefas dirigidas aos alunos, ou seja, realizam reconcepções (AMIGUES, 2004; SAUJAT, 2004; MACHADO; LOUSADA, 2010) desse documento.

Essas reconcepções/readequações, conforme podemos ver nos segmentos a seguir, estão relacionadas também com a intencionalidade do agir das/os estagiárias/os, principalmente no que diz respeito às intenções/escolhas realizadas por esses atores no que diz respeito a alterações feitas em seus planejamentos em função das reais necessidades de aprendizagem dos alunos, conforme vemos nos destaques em itálico e sublinhado duplo: 


\section{RL1}

STT2 - Preparação, realização e desenvolvimento do agir/trabalho planificado

STT2.2.: (...) esses primeiros planos foram elaborados com base em um material que nós consultamos da Revista Nova Escola, dos quais adaptamos alguns objetivos para o desenvolvimento de nossas aulas com o gênero cartaz e atividades, a partir de um fascículo didático elaborado. Porém, durante a observação foi possível constatar algumas dificuldades dos alunos para leitura e compreensão e de textos e questões gramaticais que a professora trabalhava em sala de aula (...) a partir dessas constatações e com base algumas competências e habilidades retiradas da BNCC e adequadas de acordo com o nível da turma e também da necessidade de aprendizagem dos alunos, alteramos os planos $e$ também algumas atividades do fascículo didático (...)

\section{RL2}

STT2 - Preparação do agir, realização e desenvolvimento do agir/trabalho planificado

STT2.2.1: Na realização da intervenção utilizamos uma Sequência Didática. Para isso, criamos e organizamos planos de aula, contendo os objetivos para o ensino e que guiaram a elaboração de um conjunto de atividades didáticas (...) as atividades foram organizadas em 7 (sete) módulos, para serem trabalhados em um total de 3 (três) aulas. As atividades que compõem a SD são de práticas de leitura, análise e produção textuais, trazendo as características do gênero carta do leitor. Nesse sentido, construímos as atividades a partir de três habilidades da BNCC que foram adaptadas de acordo com a necessidade da turma (...)

\section{RL3}

STT2 - Preparação do agir, realização e desenvolvimento do agir/trabalho planificado

STT2.2.1: Para realizar o desenvolvimento das atividades do projeto de intervenção, metodologicamente, realizarei um total de quatro aulas. Para construção dessas aulas, foram elaborados 4 planos de aula e uma Sequência de atividades. Para essas atividades, foram elaboradas com base em gêneros do campo da atuação na vida pública, conforme orientação da BNCC. Porém, considerando a realidade da sala de aula observada, fiz adaptações das habilidades selecionadas de acordo com o nível 
Representações do agir professoral de estagiários...

da turma (...) a turma continua alunos com níveis de aprendizagem diferentes. Isso foi observado a partir de uma atividade diagnostica que a professora permitiu que fosse realizada durante a fase de observação (...) a partir dos planos do ensino

Além dos aspectos relativos aos determinantes que marcam a caracterização e da intencionalidade do agir professoral das/os professoras/es em formação em relação ao trabalho planificado realizado, vemos também a mobilização que esses sujeitos fazem de alguns es instrumentos, isto é, de ferramentas ou modelos de agir que foram considerados por elas/es, a partir do trabalho planificado, na concretização do trabalho real em sala de aula, conforme os destaque - em negrito - nos STT a seguir:

\section{RL1}

STT3 - Preparação do agir, realização e desenvolvimento do agir/trabalho planificado

STT3.3.1: Para desenvolver o estágio de regência foram criados quatro planos de aula com dois planos com duas aulas cada um e mais dois planos com apenas uma aula, totalizando seis aulas com duração de duzentos e oitenta minutos. Esses planos são fundamentais, pois nos auxiliarão no desenvolvimento das aulas e das atividades que iremos desenvolver com os alunos juntamente com a Sequência didática elaborada (...)

\section{RL2}

STT3 - Preparação do agir, realização e desenvolvimento do agir/trabalho planificado

STT3.3.1: (...) também consideramos algumas atividades do livro do portal do professor do $\mathbf{M E C}$, mas vemos que as atividades precisavam ser melhoradas, pois não aprofundavam o gênero carta (...) e usamos o livro didático usado pela professora, que apresenta um capítulo com uma proposta didática para produção do gênero carta de leitor e que julgamos ser adequada para o trabalho de escrita com os alunos (...) 


\section{RL3}

STT3 - Preparação do agir, realização e desenvolvimento do agir/trabalho planificado

STT3.3.1: (...) durante as aulas, a partir dos planos organizados, conceituei o gênero Manifesto e apresentei exemplos desses textos aos alunos a partir da SD, objetivando provocar neles o interesse por temáticas de relevância social (...) fiz a apresentação do conceito gênero manifesto e após isso realizei a aplicação de uma atividade de interpretação na qual os alunos deveriam escrever no mínimo dois parágrafos sobre o que observaram no texto $(. .$.

A partir dos STT acima, vemos que o trabalho realizado se desenvolveu a partir de dois eixos centrais do trabalho planificado. $\mathrm{O}$ primeiro diz respeito à utilização dos planos de aula, que apresentaram direcionamentos (objetivos didáticos) e que orientaram o saber-fazer (TARDIF, 2002; LEURQUIM, 2013) das/os professores em formação nas as práticas de ensino no momento da intervenção em sala de aula.

$\mathrm{O}$ segundo diz respeito às atividades de práticas, ora elaboradas pelas/os próprias/os professores em formação, ora a partir de adaptações e/ou consultas a materiais como livros didáticos e também às atividades de domínio público, postadas no Portal do Professor do Ministério da Educação, conforme vemos nos STT destacados em negrito e itálico.

Isso mostra que tal postura os ajuda a constituírem suas profissionalidades e capacidades de pilotarem um projeto de ensino (BRONCKART, 2006) adequado às necessidades de aprendizagem das/os alunas/os. Além disso, é possível vermos também que o ensino, como uma forma trabalho, constitui-se de múltiplas atividades, desenvolvidas em diferentes situações que precisam ser investigadas, pois se inter-relacionam.

\section{Considerações finais}

Retomando ao objetivo proposto neste artigo - analisar o agir professoral de professores em formação inicial quanto às representações do trabalho que realizam em contexto de estágio, especialmente no que diz respeito ao trabalho planificado - a análise dos dados, fundamentada a partir da semântica do agir, permitiu-nos compreender, no caso em estudo, que a 
dimensão relativa ao agir/trabalho planificado (MACHADO, 2005), realizado pelas/os professores em formação, configura-se a partir de determinantes externos ligados diretamente a prescrições que são estabelecidas a partir de documentos oficiais e também de intenções e modelos de agir que esses sujeitos se apoiam para concretização do trabalho planificado e, que, em alguma medida, se relaciona com trabalho realizado no contexto da intervenção didática do estágio.

A respeito desses pontos, vemos que, apesar de as prescrições serem consideradas pelos atores implicados no agir professoral, isso não anula a autonomia desses sujeitos no que diz respeito à planificação e à modelização didática (ROJO, 2001) que realizam para o trabalho efetivamente realizado em sala de aula a partir do que foi projetado/planejado.

Isso mostra também que a/o professora/o em formação apresenta consciência a respeito da necessidade de conhecer e mobilizar saberes oriundos dessas prescrições, mas também reconhecer a necessidade de adaptá-los às necessidades de seu contexto de ensino e às necessidades de aprendizagem dos alunos.

Além disso, vemos que ao tematizarem tanto a caracterização quanto a preparação e o desenvolvimento do agir (a tarefa de planejar os planos de aulas e as atividades), as/os estagiárias/os apreenderam o agir em sua singularidade, portanto, mobilizam saberes teóricos e práticas no dialógico com aquilo que foi observado no contexto de atuação - escola-campo do estágio e sala de aula -, objetivando darem sentidos ao trabalho planificado que fizeram a partir das necessidade de aprendizagens dos alunos.

Por fim, consideramos como ponto relevante a necessidade de outros estudos que possam trazer ao campo de discussão também o trabalho realizado e real a partir do foi proposto no trabalho planificado em contexto de formação inicial, como é o caso do estágio. Consideramos tal ponto como relevante por entendermos que a sala de aula da educação básica constituise, sob o ponto de vista de um locus de trabalho, como um lugar, que pode também revelar nuances do trabalho do professor a partir de outros determinantes que lhe são (im)postos a partir dessa realizado.

De um modo geral, os dados analisados demonstram que o professor em formação, em contexto de estágio, não se configura apenas como um "mero executor de prescrições que incidem sobre sua forma de pensar o ensino e a aprendizagem de acordo com uma determinada teoria" (MACHADO, 2007, p.90), pois, conforme visto, os participantes desta 
pesquisa lançam mão de múltiplos instrumentos, ferramentas para e na realização de seu agir professoral.

\section{Referências}

ABREU-TARDELLI, L. trabalhodoprofessor@chateducacional.com.br: Aportes para compreender o trabalho do professor iniciante em EAD. 2006. 216f. (Tese de doutorado em Linguística Aplicada e Estudos da Linguagem) - Programa de Pós-graduação em Linguística Aplicada e Estudos da Linguagem, PUC, São Paulo, 2006.

AMIGUES, R. Trabalho do professor e trabalho de ensino. In: MACHADO, A. R. (org.) $\mathbf{O}$ ensino como trabalho: uma abordagem discursiva, Londrina: EDUEL: 35-54, 2004.

PESSOA, R. R. O estágio e o desafio decolonial: problematizações sobre as relações interpessoais de seus/suas agentes. MOARA, Belém, v. 51, 2019. p. 75-96.

Disponível em:

https://periodicos.ufpa.br/index.php/moara/article/view/7331>. Acesso em 12 abr. 2020.

BORTONI-RICARDO, S. M. O professor pesquisador: introdução à pesquisa qualitativa. São Paulo: Parábola Editorial, 2008.

BRONCKART, J. P. Atividade de linguagem, textos e discursos: por um interacionismo sociodiscursivo. 2.ed. São Paulo: Educ, 2009.

BRONCKART, J. P.; MACHADO, A. R. Procedimentos de análise de textos sobre o trabalho educacional. In: MACHADO, A. R. (Org.). O ensino como trabalho: uma abordagem discursiva. Londrina: Eduel, 2004. p. 131-163.

BRONCKART, J.P. Atividade de linguagem, discurso e desenvolvimento humano. Tradução Anna Rachel Machado, Maria de Lourdes Meirelles Matencio. Campinas-SP: Mercado das Letras, 2006. 
Representações do agir professoral de estagiários...

BRONCKART, J.P. O agir nos discursos: das concepções teóricas às concepções dos trabalhadores. Tradução Anna Rachel Machado e Maria de Lourdes Meirelles Matencio. Campinas-SP: Mercado de Letras, 2008.

BUENO, L. A construção de representações sobre o trabalho docente: o papel do estágio. 2017. 223f. (Tese de Doutorado em Linguística Aplicada e Estudos da Linguagem) - Pontifícia Universidade Católica de São Paulo. Programa de Pós-graduação em Linguística Aplicada e Estudos da Linguagem, São Paulo, 2007.

BULEA, E. Linguagem e efeitos desenvolvimentais da interpretação da atividade. Campinas, São Paulo: Mercado de Letras, 2010.

BULEA, E.; BRONCAKRT, J.P. As potencialidades praxiológicas e epistêmicas dos (tipos de) discursos. SCRIPTA, Belo Horizonte, v. 12, n. 22, 2008. Disponível em:

http://periodicos.pucminas.br/index.php/scripta/article/view/4433>. Acesso em 12 abr. 2020.

BULEA, E.; LEURQUIN, E; CARNEIRO, F. O agir do professor e as figuras de ação: por uma análise interacionista. In: BUENO, L; LOPES, M; CRISTOVÃ̃, V. (Org.). Gêneros textuais e formação inicial: uma homenagem à Malu Matêncio. Campinas, São Paulo: Mercado de Letras, 2013. p. 109-117.

CAVALCANTI, M. Educação linguística na formação de professores de línguas: intercompreensão e práticas translíngues. In: MOITA LOPES, L. P. (Org). Linguística Aplicada na Modernidade Recente: Festschrift para Antonieta Celani. São Paulo: Parábola, 2013. p. 211- 226.

CLOT, Y. A função psicológica do trabalho. 2 ed. Tradução de Adail Sobral. Rio de Janeiro, Petrópolis: Vozes, 2007.

DENZIN, N.K.; LINCOLN, Yvonna. A disciplina e a pratica da pesquisa qualitativa. In: DENZIN, N. K.; LINCOLN, Y. (Org.). Planejamento da pesquisa qualitativa: teorias e abordagens. 2 ed. Porto Alegre: ARTMED, 2006. 
FAITA, D. Gêneros de discurso, gêneros de atividade, análise da atividade do professor. In: MACHADO, A. R. (Org.). O ensino como trabalho: uma abordagem discursiva. Londrina: Eduel, 2004. p. 53-80.

GURGEL, M.; LEURQUIN, E. O estágio na formação inicial de professores de língua materna: uma abordagem linguística e enunciativa de representações. Revista Desempenho, v. 1, n. 25, 15 jun. 2016.

KLEIMAN, A. Agenda de pesquisa e ação em Linguística Aplicada: problematizações. In: MOITA LOPES, L. P. Linguística Aplicada na modernidade recente: festschrift para Antonieta Celani. São Paulo: Parábola, 2013.

LEURQUIN, E. V. L. F. O que dizem os professores sobre seu agir professoral? In: GERHARDT, A. F. L. M. (org.). Revista da ANPOLL. Campinas: Pontes, 2013a, v. 1, p. 299-332.

LEURQUIN, E. V. L.F.; MENDES, K. A formação de professores para falantes de outras línguas: rotas e (novas) perspectivas. In: SÁ, R. L.; GUEDES, R. S. (org.). PFO Português para falantes de outras línguas Materiais didáticos, formação de professores e ensino de gramática. Campinas: Pontes, 2017, v. 01, p. 95-112.

LOUSADA, E. G.; ABREU-TARDELLI, L. S.; MAZZILLO, T. O trabalho do professor: revelações possíveis pela análise do agir representado nos textos. In: GUIMARÃES, A. M. M. et al. (org.). O interacionismo sociodiscursivo: questões epistemológicas e metodológicas. São Paulo: Mercado de Letras, 2007. pp.237-256.

MACHADO, A. R. Por uma concepção ampliada do trabalho do professor. In: GUIMARÃES, A. M. M; MACHADO, A. R.; COUTINHO, A. (org.) O Interacionismo Sociodiscursivo: questões epistemológicas e metodológicas. São Paulo: Mercado de Letras, 2007, p. 77-97. 
Representações do agir professoral de estagiários...

MACHADO, A. R; LOUSADA, E. A apropriação de gêneros textuais pelo professor: em direção ao desenvolvimento pessoal e à evolução do "métier". Linguagem em (Dis)curso, Palhoça, SC, v. 10, n. 3, 2010.

MACHADO, A.R. Por uma concepção ampliada do trabalho do professor. In: GUIMARÃES, A.M.M., MACHADO, A.R. e COUTINHO, A. (org.). 0 Interacionismo Sociodiscursivo: Questões epistemológicas e metodológicas. Campinas: Mercado de Letras, 2009.

MACHADO, A.R; BRONCKART, J.P. De que modo os textos Oficiais prescrevem o Trabalho do Professor? Análise Comparativa de Documentos Brasileiros e Genebrinos. Revista de Documentação de Estudos em Linguística Teórica e Aplicada Delta. São Paulo, vol. 21, n.2, 2005.

MILLER, I. K. de. Formação de professores de línguas: da eficiência à reflexão crítica e ética. In. MOITA LOPES, L. P. Linguística Aplicada na modernidade recente. Editora Parábola, 2013, p. 99-121.

MOITA LOPES, L.P. (org.) Linguística Aplicada na modernidade recente. São Paulo: Parábola, 2013.

MOITA LOPES, L. P. Gênero, sexualidade, raça em contextos de letramentos escolares. In: MOITA LOPES, L.P. (org.) Linguística Aplicada na modernidade recente. São Paulo: Parábola, 2013, pp. 227-248.

SAUJAT, F. O trabalho do professor nas pesquisas em educação: um panorama. In: MACHADO, A. R. (org.). O ensino como trabalho: uma abordagem discursiva. Londrina: Eduel, 2004, p. 3-34.

SILVA, W. R. Reflexão pela escrita no estágio supervisionado da licenciatura: pesquisa em Linguística Aplicada. Campinas: Pontes Editores, 2014.

TARDIF, M. Saberes docentes e formação profissional. Petrópolis: Vozes, 2002. 
Rosivaldo Gomes

Recebido em: 22/07/2020

Aceito em: 05/12/2020

Title: Trainees' representations of teacher's actions in supervised internship reports: what do teachers in training say about their planned work? 